11,12

\title{
Фазовый переход первого рода в нанотубулярном диоксиде титана
}

\author{
(C) А.А. Сушникова ${ }^{1,2}$, А.А. Валеева ${ }^{2,3}$, И.Б. Дорошева ${ }^{1,2}$, А.А. Ремпель ${ }^{1,2}$ \\ ${ }^{1}$ Институт металлургии УрО РАН, \\ Екатеринбург, Россия \\ ${ }^{2}$ Уральский федеральный университет, \\ Екатеринбург, Россия \\ ${ }^{3}$ Институт химии твердого тела УрО РАН, \\ Екатеринбург, Россия \\ E-mail: sushnikova.ann@gmail.com
}

Поступила в Редакцию 8 июля 2021 г.

В окончательной редакции 13 июля 2021 г.

Принята к публикации 16 июля 2021 г.

\begin{abstract}
Нанотрубки диоксида титана $\mathrm{TiO}_{2}$ длиной около $16 \mathrm{mkm}$ и диаметром около $100 \mathrm{~nm}$ были синтезированы методом анодного окисления титановой фольги. В качестве электролита был использован фторсодержащий водный раствор этиленгликоля. Предложенные в настоящей работе условия синтеза позволили получить толстый слой нанотрубок, механически отделить нанотубулярный слой от титановой подложки и исследовать его как самостоятельный функциональный материал. Выполненный анализ на растровом электронном микроскопе и определение удельной поверхности методом Брунауэра-Эммета-Теллера позволили получить данные о морфологии образцов. Анализ результатов исследований, полученных методами рентгенофазового, термогравиметрического анализа, дифференциальной сканирующей калориметрии позволили определить температуру фазового перехода аморфной фазы в кристаллическую фазу со структурой анатаза (пр. гр. I4/ $\mathrm{amd}$ ). Наблюдаемый фазовый переход первого рода происходит при температуре около $350^{\circ} \mathrm{C}$.
\end{abstract}

Ключевые слова: нанотубулярные пленки диоксида титана, анодное окисление, фазовый переход, анатаз, ТГ, ДСК.

DOI: $10.21883 /$ FTT.2021.12.51659.17s

\section{1. Введение}

В настоящее время наноструктурированный диоксид титана $\mathrm{TiO}_{2}$ является перспективным функциональным материалом [1] для таких областей как: источники возобновляемой энергии [2], неорганические сорбенты [3], ячейки резистивной памяти [7], фотокатализаторы [4,5], в том числе для водородной энергетики [6].

На сегодняшний день существует множество методов синтеза наноструктурированного $\mathrm{TiO}_{2}$ с различной морфологией и структурой: гидролиз солей титана $[9,10]$, золь-гель [11,12], гидротермальный синтез [13], а так же анодное окисление [7,14,15].

Существуют четыре наиболее распространенных фазовых состояния диоксида титана, а именно аморфное, анатаз, брукит и рутил. Согласно литературе, температура фазового перехода из аморфного состояния в анатаз отличается для различных методов синтеза и зависит от конечной морфологии частиц $[10,14,16]$. На данный момент отсутствуют работы по термогравиметрическому анализу (ТГ) и дифференциальной сканирующей калориметрии (ДСК) для нанотубулярного диоксида титана, отделенного от подложки, синтезированного методом анодного окисления. Согласно данным ДСК [15], на нанотрубках $\mathrm{TiO}_{2}$, полученных анодированием титановой фольги, отсутствуют прямые данные о фазовом переходе в кристаллическую фазу. В связи с этим, целью рабо- ты является получение нанотубулярного слоя диоксида титана методом анодного окисления, изучение его морфологии и фазового превращения при температурной обработке.

\section{2. Экспериментальная часть}

Нанотубулярный диоксид титана был синтезирован методом анодирования титановой фольги толщиной $200 \mathrm{mkm}$ на установке Digma, состоящей из электрохимической ячейки, термостата и источника питания [7]. Перед использованием фольга помещалась в раствор кислот $\left(\mathrm{HNO}_{3}: \mathrm{HF}: \mathrm{H}_{2} \mathrm{O}=1: 1: 20\right)$, а затем промывалась дистиллированной водой. Анодирование проходило в потенциостатическом режиме при напряжении $60 \mathrm{~V}$ в течение $60 \mathrm{~min}$ с поддержанием температуры электролита на уровне $20^{\circ} \mathrm{C}$. В качестве электролита был использован фторсодержащий раствор этиленгликоля с добавлением воды в пропорции $\mathrm{NH}_{4} \mathrm{~F}: \mathrm{H}_{2} \mathrm{O}_{\text {дист }}: \mathrm{C}_{2} \mathrm{H}_{6} \mathrm{O}_{2}=1: 2: 98$ по массе. Все химические реагенты имели класс чистоты ЧДА. После анодирования образец извлекался из электрохимической ячейки и промывался струей дистиллированной воды, затем просушивался. В дальнейшем слой нанотрубок титана отделялся механически. Отжиг $\mathrm{TiO}_{2}$ проводился на воздухе в муфельной печи SNOL при температурах $180,240,300$ и $350^{\circ} \mathrm{C}$ в течение $4 \mathrm{~h}$. 
Рентгенофазовый анализ (РФА) синтезированного нанотубулярного слоя $\mathrm{TiO}_{2}$ был выполнен в $\mathrm{Cu} K_{\alpha 1,2}$ излучении на дифрактометре STOE „STADI-P“. Рентгенограммы снимались в режиме пошагового сканирования с $\Delta(2 \theta)=0.03^{\circ}$ в интервале углов $2 \theta$ от 10 до $80^{\circ}$ с высокой статистикой. Поликристаллический кремний с периодом решетки $543.07 \mathrm{pm}$, был использован в качестве внешнего стандарта. Для идентификации фаз использовали „Базу порошковых стандартов - ICDD, USA, Release 2016“. Фазовый анализ проведен с помощью программы Powder Cell 2.4. Предварительно отделенный от титановой фольги нанотубулярный слой $\mathrm{TiO}_{2}$ перетирался в агатовой ступке.

Для определения удельной площади поверхности был использован анализатор Gemini VII 2390. Полученные изотермы адсорбции и десорбции азота при температуре $77.3 \mathrm{~K}$ обрабатывались в соответствии с теорией Брунауера-Эммета-Теллера (БЭТ). Предварительная дегазация проводилась при температуре $150^{\circ} \mathrm{C}$ с дальнейшим использованием гелия. Исследование морфологии нанотрубок было выполнено на растровом электронном микроскопе (PЭM) SIGMA VP (Carl Zeiss) в режиме высокого вакуума со вторичным электронным детектоpoм (InLens). Исследования методом дифференциальной сканирующей калориметрии (ДСК) и термогравиметрии (ТГ) проводились без предварительной термической обработки синтезированных нанотрубок $\mathrm{TiO}_{2}$ на ТГ-ДСК анализаторе Netzsch STA 409 PC Luxx. Нагрев образцов нанотубулярного слоя осуществлялся в корундовом тигле в атмосфере аргона со скоростью $20^{\circ} \mathrm{C} / \mathrm{min}$.

\section{3. Результаты и обсуждение}

Согласно РЭМ-микрофотографиям (рис. 1), синтезированный методом анодного окисления нанотубулярный слой диоксида титана достиг толщины около $16 \mathrm{mkm}$, диаметр нанотрубок составил около $100 \mathrm{~nm}$, а толщина стенок трубки - около $35 \mathrm{~nm}$. Предложенные в данной работе условия синтеза позволили получить большие

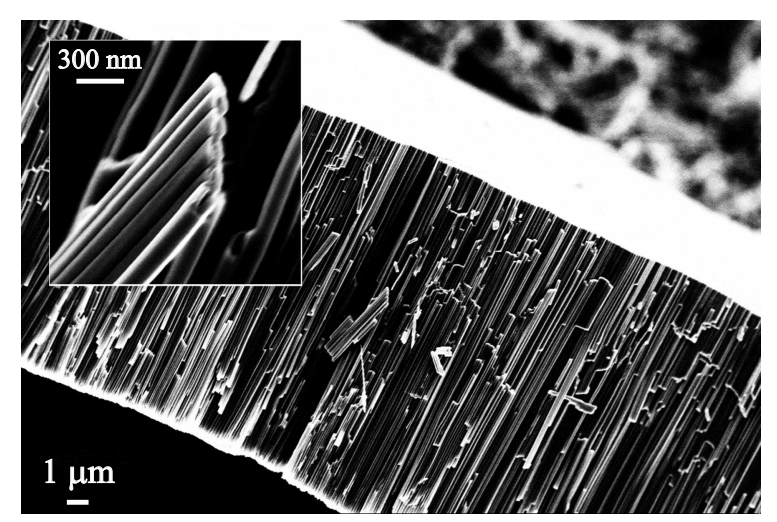

Рис. 1. Микрофотография поперечного сечения нанотубулярного слоя $\mathrm{TiO}_{2}$. На вставке представлены отдельные нанотрубки.

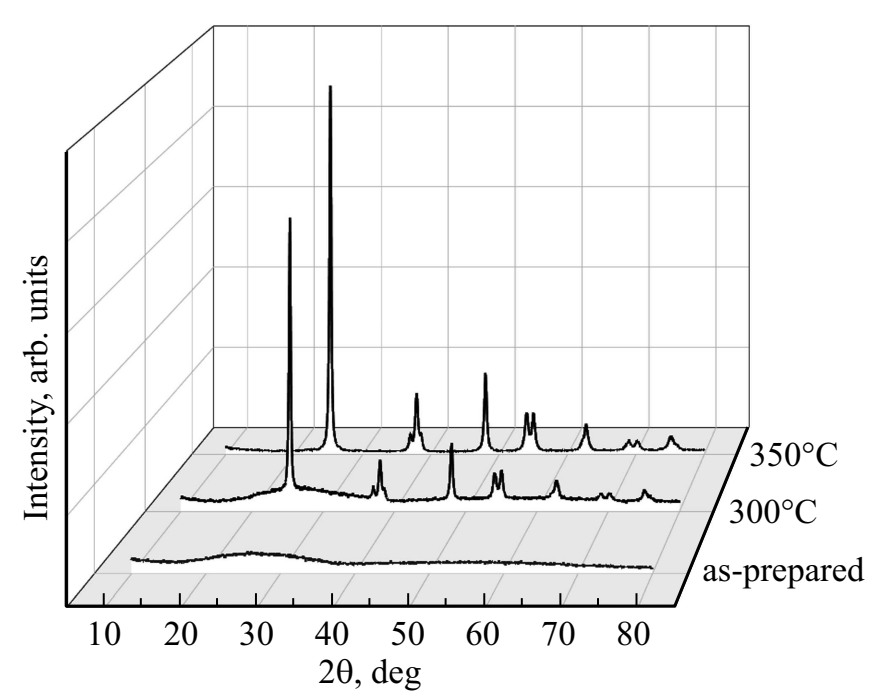

Рис. 2. Рентгенограммы синтезированного нанотубулярного диоксида титана и отожженного при разных температурах на воздухе.

по площади (несколько $\mathrm{cm}^{2}$ ) нанотубулярные слои, которые можно легко отделить механически.

Рентгенограммы синтезированного нанотубулярного слоя и отожженных при температуре 300 и $350^{\circ} \mathrm{C}$ образцов показаны на рис. 2. Согласно данным РФА, синтезированные нанотубулярные слои $\mathrm{TiO}_{2}$ имеют аморфную структуру. Отжиг при $300^{\circ} \mathrm{C}$ в течение 4-xh приводит к формированию фазы анатаз. При этом наличие диффузного гало после отжига при $300^{\circ} \mathrm{C}$ в течение $4-\mathrm{xh}$ на воздухе говорит о неполной кристаллизации. Отжиг на воздухе при более высокой температуре, а именно при $350^{\circ} \mathrm{C}$ в течение 4-x h приводит к завершению фазового перехода из аморфного состояния в кристаллическое, происходит образование полностью кристаллической фазы анатаз. Согласно данным полнопрофильного анализа, в результате фазового перехода образовался диоксид титана в фазе анатаз с тетрагональной структурой (пр. гр. I41/amd) с параметрами кристаллической решетки: $a=b=379.29 \mathrm{pm}, c=948.46 \mathrm{pm}$, $\lambda=\beta=\gamma=90^{\circ}$, что соответствует фазе анатаз согласно литературным данным [6].

Согласно анализу удельной поверхности, величина удельной площади поверхности синтезированного нанотубулярного слоя диоксида титана составляет около $14 \mathrm{~m}^{2} / \mathrm{g}$, отжиг при 180 и $240^{\circ} \mathrm{C}$ в течении $4-\mathrm{xh}$ существенно не изменяют величину удельной площади поверхности, а повышение температуры до $300^{\circ} \mathrm{C}$ незначительно повышает значение удельной площади поверхности до $18 \mathrm{~m}^{2} / \mathrm{g}$ (рис. 3). Отжиг при температуре $350^{\circ} \mathrm{C}$ приводит к существенному повышению удельной площади поверхности до $51 \mathrm{~m}^{2} / \mathrm{g}$. Увеличение площади удельной поверхности может быть вызвано несколькими факторами: во-первых, плотно прилегающие одна к другой нанотрубки в результате нагрева, и дальнейшего 


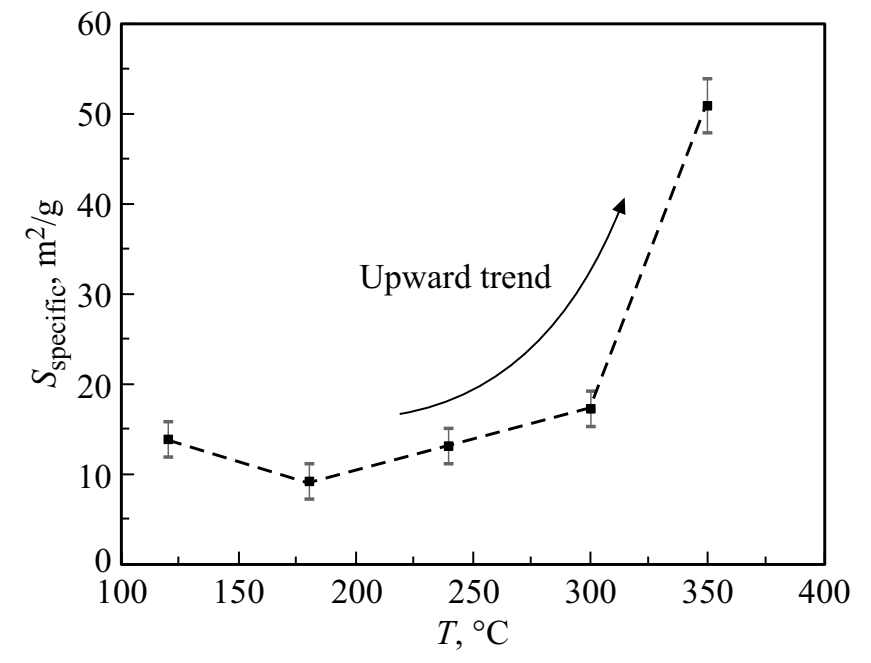

Рис. 3. Зависимость удельной площади поверхности нанотубулярного диоксида титана от температуры отжига на воздухе.

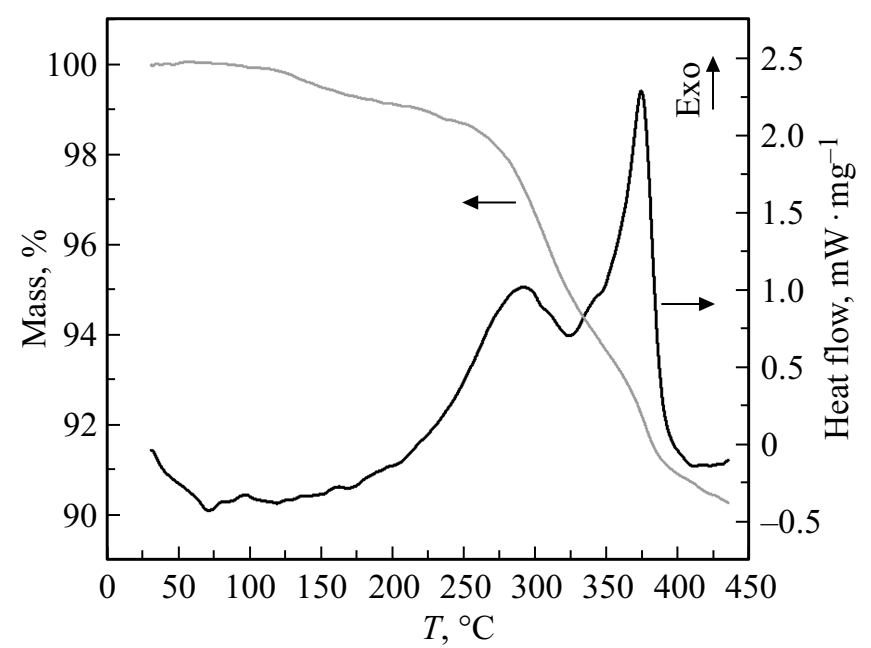

Рис. 4. ТГ-ДСК-анализ нанотубулярного диоксида титана.

остывания, частично отделяются друг от друга, что приводит к образованию новых поверхностей, во-вторых, при термообработке остатки органического электролита разлагаются на углекислый газ и воду, что приводит к очищению внутренней поверхности нанотрубок.

На рис. 4 представлены результаты ТГ-ДСК-анализа нанотубулярного диоксида титана. Согласно кривой ТГ, потеря массы происходит в несколько этапов. На первом этапе до $250^{\circ} \mathrm{C}$ происходит удаление с поверхности нанотобулярного массива $\mathrm{TiO}_{2}$ физически адсорбированных воды и этиленгликоля. Потеря веса в связи с данной десорбцией составляет около $1.3 \%$. Данный процесс сопровождается обширным эндотермическим пиком на ДСК кривой. На втором этапе в диапазоне температур от 250 до $400^{\circ} \mathrm{C}$ происходит активная потеря массы - на 8.4\%, связанная с термическим разложением этиленгликоля на воду и углекислых газ. Этому участку соответствуют три экзотермических пика на кривой ДСК.

Пики на кривой ДСК с максимумом при 290 и $372^{\circ} \mathrm{C}$ сопровождаются наибольшей скоростью потери массы и относятся к термическому разложению этиленгликоля, что согласуется с данными более ранних работ $[15,11,13]$. Между пиками на кривой ДСК в интервале от 325 до $350^{\circ} \mathrm{C}$ наблюдается плечо со слабым экзотермическим эффектом, сопровождающимся пологим участком на кривой ТГ. В этом температурном интервале происходит фазовый переход $\mathrm{TiO}_{2}$ из аморфной фазы в кристаллическую со структурой анатаз (пр.гр. I4/amd). Поскольку фазовый переход сопровождается скачкообразным тепловым эффектом и не удовлетворяет критерию Ландау для фазовых переходов второго рода можно утверждать, что происходящий фазовый переход является фазовым переходом первого рода. Незначительная потеря массы на этом участке составляет $1.4 \%$, что связано с продолжением десорбции электролита. Стоит отметить, что данное плечо на кривой ДСК в работе [15] отсутствует из-за эндотермического пика от разложения органического растворителя на поверхности нанотрубок, перекрывающего экзотермический пик кристаллизации в диапазоне температур ниже $300^{\circ} \mathrm{C}$. Данный эффект так же подтверждает сильная потеря массы - до 5\%. Однако в работе [14] температура кристаллизации на нанотрубках $\mathrm{TiO}_{2}$ сопоставима с результатами настоящей работы и составляет $343^{\circ} \mathrm{C}$. Экзотермический пик, соответствующий переходу из аморфного состояния в анатаз, отчетливо виден на кривой ДСК.

Существуют исследования ДСК на наноразмерном диоксиде титана с нетубулярной формой частиц. Температура кристаллизации, наблюдаемая в виде экзотермических пиков на ДСК, при фазовом переходе из аморфной фазы в фазу анатаз выше, чем на нанотрубках: $385^{\circ} \mathrm{C}[16], 436^{\circ} \mathrm{C}[10], 400-480^{\circ} \mathrm{C}[17]$, и $360-450^{\circ} \mathrm{C}[9]$. Вероятно, это связано с меньшим размером наночастиц и их большей структурной разупорядочностью.

\section{4. Заключение}

Предложенные в настоящей работе условия анодирования позволили синтезировать толстые пленки нанотрубок диоксида титана (до $16 \mathrm{mkm}$ ), которые легко механически отделяются и дают возможность использовать их в практике без титановой фольги.

Методами РФА, ДСК установлено, что фазовый переход первого рода аморфная фаза-анатаз происходит при температуре выше $240^{\circ} \mathrm{C}$, максимум интенсивности процесса наблюдается при температурах около $350^{\circ} \mathrm{C}$.

Согласно данным РФА, БЭТ, отжиг приводит к изменению атомной структуры, увеличению удельной площади поверхности с 14 до $51 \mathrm{~m}^{2} / \mathrm{g}$ и очищению поверхности от органических примесей, что очень важно для практи- 
ческого применения нанотубулярного диоксида титана в фотокатализе.

\section{Благодарности}

Авторы выражают особую благодарность Д.А. Ягодину за проведение исследований методами ТГ и ДСК.

\section{Финансирование работы}

Работа выполнена по проекту РФФИ 20-03-00299 и гос. заданиям ИМЕТ УрО РАН и ИХТТ УрО РАН.

\section{Конфликт интересов}

Авторы заявляют, что у них нет конфликта интересов.

\section{Список литературы}

[1] A.A. Rempel, A.A. Valeeva, A.S. Vokhmintsev, I.A. Weinstein. Russ. Chem. Rev. 90 (2021). DOI: 10.1070/RCR4991

[2] T.S Natarajan, K. Natarajan, H.C. Bajaj, R.J. Tayade. Ind. Eng. Chem. Res. 50, 13, 7753 (2011).

[3] A.V. Volkov, V.V. Polyanskaya, M.A. Moskvina, S.B. Zezin, A.I. Dementev, A.L. Volynskii, N.F. Bakeev. Nanotechnol. Russ. 7, 7, 377 (2012).

[4] A.A. Valeeva, I.B. Dorosheva, E.A. Kozlova, R.V. Kamalov, A.S. Vokhmintsev, D.S. Selishchev, A.A. Saraev, E.Yu. Gerasimov, I.A. Weinstein, A.A. Rempel. J. Alloys Compd. 796, 293 (2019).

[5] A.A. Valeeva, E.A. Kozlova, A.S. Vokhmintsev, R.V. Kamalov, I.B. Dorosheva, A.A. Saraev, I.A. Weinstein, A.A. Rempel. Sci. Rep. 8, 1, 9607 (2018).

[6] A.A. Valeeva, I.B. Dorosheva, E.A. Kozlova, A.A. Sushnikova, A.Y. Kurenkova, A.A. Saraev, H. Schroettner, A.A. Rempel. Int. J. Hydrogen Energy 46, 32, 16917 (2021).

[7] A.S. Vokhmintsev, I.A. Weinstein, R.V. Kamalov, I.B. Dorosheva. Bull. Russ. Acad. Sci.: Phys. 78, 9, 932 (2014).

[8] W. Li, T. Bak, A. Atanacio, J. Nowotny. Appl. Catal. B 198, 243 (2016).

[9] D. Švadlák, J. Shánelová, J. Málek, L.A. Pérez-Maqueda, J. Manuel Criado, T. Mitsuhashi. Thermochim. Acta 414, 137 (2004).

[10] S.A. Mansour. Ceram. Int. 45, 2, 2893 (2019).

[11] Z. Baolong, C. Baishun, Sh. Keyu, H. Shangjin, L. Xiaodong, D. Zongjie, Ya. Kelian. Appl. Catal. B 40, 253 (2003).

[12] C.G. Silva, J.Lu. Faria. Photochem. Photobiol. Sci. 8, 705 (2009).

[13] X. Wang, Li-Li Wang, D. Guo, Lu-Lu Ma, Ba. Zhu, P. Wang, G. Wang, Shou-Min Zhang, W. Huang. Catal. Today 327, 182 (2019).

[14] Z. Xu, S. Wang, C. Ma, K. Luo, F. Fang. Phys. Status Solidi A 216, 6, 1800836 (2019).

[15] J. Liao, S. Lin, N. Pan, S. Li, X. Cao, Ya. Cao. Mater. Charact. 66, 24 (2012).

[16] S. Villa, V. Caratto, F. Locardi, S. Alberti, M. Sturini, Andrea, F.Maraschi, F. Canepa, M. Ferretti. Mater. 9, 771 (2016).

[17] H. Xie, Q. Zhang, T. Xi, J. Wang, Ya. Liu. Thermochim. Acta 381, 45 (2002).

Редактор К.В. Емщев 